\title{
Kinetics and Mechanism of Ruthenium(III) Catalyzed Oxidation of Butanone and Uncatalyzed Oxidation of Cychlohexanone by Cerium(IV) in Acid Sulphate Medium
}

\author{
Priyamvada Sharma*, Shalini Hemkar, C.L. Khandelwal, and P. D. Sharma \\ Department of Chemistry, University of Rajasthan, Jaipur-302004, India. \\ ${ }^{*}$ E-mail: Priva2485@gmail.com
}

(Received August 8, 2011; Accepted December 9, 2011)

\begin{abstract}
The kinetics of ruthenium(III) chloride catalyzed oxidation of butanone and uncatalyzed oxidation of cyclohexanone by cerium(IV) in sulphuric acid medium have been studied. The kinetic rate law(I) in case of butanone conforms to the proposed mechanism.

$$
-\frac{1}{2} \frac{\mathrm{d}\left[\mathrm{Ce}^{\mathrm{IV}}\right]}{\mathrm{dt}}=\frac{\mathrm{kK}\left[\mathrm{Ru}^{\mathrm{III}}\right][\text { butanone }]}{1+\mathrm{K}[\text { butanone }]}
$$

However, oxidation of cyclohexanone in absence of catalyst accounts for the rate eqn. (2).

$$
-\frac{1}{2} \frac{\mathrm{d}\left[\mathrm{Ce}^{\mathrm{IV}}\right]}{\mathrm{dt}}=\frac{\left(\mathrm{k}_{1}+\mathrm{k}_{1} \mathrm{~K}^{\prime}\left[\mathrm{H}^{+}\right]\right)\left[\mathrm{Ce}^{\mathrm{IV}}\right][\text { Cyclohexanone }]}{1+\mathrm{K}_{3}\left[\mathrm{HSO}_{4}^{-}\right]}
$$

Kinetics and activation parameters have been evaluated conventionally. Kinetically preferred mode of reaction is via ketonic and not the enolic forms.
\end{abstract}

Key words: Kinetics, Ruthenium(III), Oxidation, Ketones, Cerium(IV)

\section{INTRODUCTION}

There are numerous mechanistic studies of oxidation of organic compounds apart from useful synthetic studies ${ }^{1}$ in which cerium(IV) has been employed as an oxidant in acid sulphate medium. The speciation of sulphato-cerium (IV) species in sulphuric acid medium still requires further details.-5 Moreover, cerium(IV) has also been employed as an oxidant in oxidimetric analysis of both metals and non-metals latter being acid medium ${ }^{6}$. So far the kinetics of cerium(IV) reactions is concerned, an intermediate complex between oxidant and substrate is generally considered to be the preferred mode of electron transfer. Such an intermediate complex has also been established both kinetically and spectrophotometrically in large number of reactions.

The kinetics of oxidation of ketones ${ }^{7}$ are reported with variance of the results owing to the reactivity of ketone and its enol form.

These were the observations that prompted us to undertake the kinetics of ketones such as butanone and cyclohexanone with cerium(IV) in sulphuric acid medium from the following view points:

First delineation of sulphato-cerium(IV) species partic- ipate in reactions of cerium(IV) more in acid sulphate medium is required owing to inter-play of such species. Thus ruthenium(III) chloride catalyzed oxidation of butanone was taken as a test case.

Secondly, since the co-ordination sites of cerium(IV) are saturated by sulphate ions, whether or not such sulphato-cerium(IV) species form any intermediate complex with ketones or its tautomeric enol form. Thirdly, which species of the substrate participates in the reaction is of interest $^{8-12}$ in view of controversial reports in the literature.

\section{EXPERIMENTAL}

\section{Materials and methods}

The stock solution of cerium(IV) was prepared by dissolving cericammoniumnitrate or cericsulphate (E. Merck) in $\mathrm{H}_{2} \mathrm{SO}_{4}\left(5.0 \mathrm{~mol} \mathrm{dm}^{-3}\right)$, the solution was heated near to boiling in case of the former to decompose both nitrate and ammonium ions before making it up to the desired volume by addition of water. The resulting solution was standardized by titrating against ferrous ammonium sulphate employing ferroin as an indicator.

All other chemicals/reagents employed in this study were of either AnalarR or guaranteed reagent grade and 
were used as received.

Doubly distilled water was employed throughout the study, the second distillation was from alkaline permanganate solution in an all glass apparatus.

\section{Method}

The kinetics of the reactions were carried out in glass stoppered Erlenmeyer flasks which were immersed in a water-bath thermostated at $\pm 0.1^{\circ} \mathrm{C}$ unless stated otherwise. All other ingredients of the reaction mixture except cerium(IV) were taken in these flasks, cerium(IV) was taken in another flask. When these solutions attained equilibrated bath temperature, an aliquot of required cerium(IV) concentration was added into the reaction mixture and the time of initiation of the reaction was recorded when half of the contents from the pipette were released in to reaction mixture.

An aliquot $\left(5\right.$ or $\left.10 \mathrm{~cm}^{3}\right)$ of the reaction mixture was withdrawn periodically and then discharged into an icecold $\mathrm{H}_{2} \mathrm{SO}_{4}$ solution ( $\left.1.0 \mathrm{~mol} \mathrm{dm}^{-3}\right)$; remaining cerium(IV) was assayed by titrating against ferrousammoniumsulphate solution employing ferroin as an indicator. Without any interference from other reaction ingredients.

Initial rates $\left(\mathrm{k}_{\mathrm{i}}, \mathrm{mol} \mathrm{dm}^{-3} \mathrm{~s}^{-1}\right)$ were computed ${ }^{13}$ employing plane mirror method. Pseudo first order plots ([ketone] $>>[\mathrm{Ce}(\mathrm{IV})]$ ) were made wherever reaction conditions permitted. Second order plots were also made for comparable concentrations of the reactants by plotting log $\left[\mathrm{Ce}(\mathrm{IV})_{\mathrm{t}}\right] /[\text { ketone }]_{\mathrm{t}}$ or $\log [\text { ketone }]_{\mathrm{t}} /\left[\mathrm{Ce}(\mathrm{IV})_{\mathrm{t}}\right]$. Triplicate rate measurements were reproducible to within $\pm 5 \%$.

\section{Stoichiometry}

The reaction stoichiometry was similar as was observed in perchloric acid medium i.e. two moles of the oxidant react with a mole of the substrate under experimental conditions of kinetics.

\section{RESULTS AND DISCUSSION}

The concentration of cerium(IV) was varied from 1.0 $\times 10^{-3}$ to $5.0 \times 10^{-3} \mathrm{~mol} \mathrm{dm}^{-3}$ at fixed concentrations of other reaction ingredients and $[\mathrm{RuIII}]=5.0 \times 10^{-6}$ at $35^{\circ} \mathrm{C}$. Initial rates $\left(\mathrm{k}_{\mathrm{i}}, \mathrm{mol} \mathrm{dm}^{-3} \mathrm{~s}^{-1}\right)$ were found to be independent of gross initial concentration of cerium(IV) conforming zero order with respect to the oxidant. Typical zero order plots are shown in Fig. 1.

The concentration of butanone was varied from $5.0 \times 10^{-3}$ to $5.0 \times 10^{-2} \mathrm{~mol} \mathrm{dm}^{-3}$ at fixed concentrations of other reaction ingredients at 30,35 and $40{ }^{\circ} \mathrm{C}$ respectively. The plot

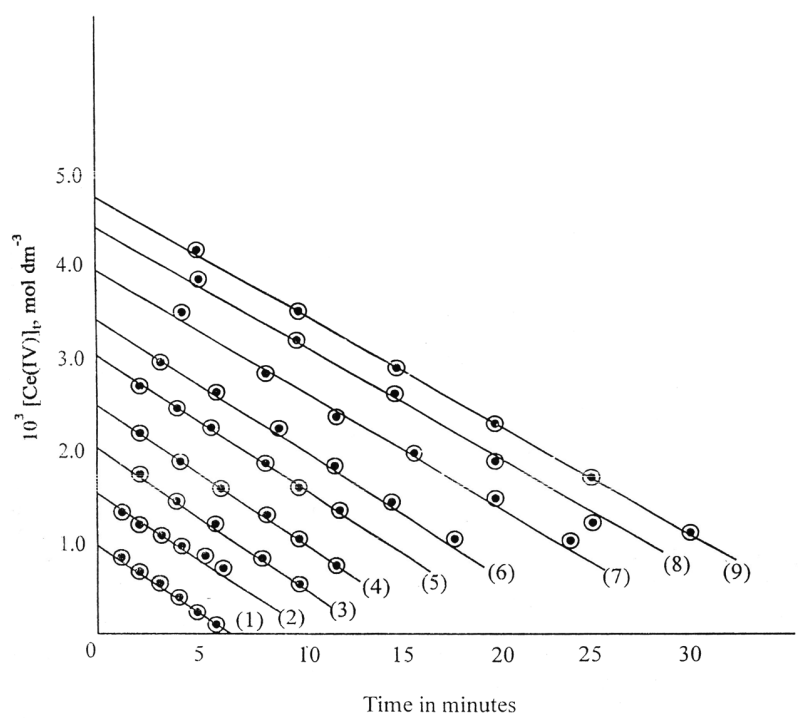

Fig. 1. ZERO ORDER PLOTS [Butanone $]=4.0 \times 1^{-2} \mathrm{~mol} \mathrm{dm}^{-3}$; $\left[\mathrm{H}_{2} \mathrm{SO}_{4}\right]=0.5 \mathrm{~mol} \mathrm{dm}^{-3}[\mathrm{Ru}(\mathrm{III})]=5.0 \times 10^{-6} \mathrm{~mol} \mathrm{dm}^{-3} ; 35^{\circ} \mathrm{C}[\mathrm{Tl}(\mathrm{III})]$ $=$ (1) $1.0 \times 10^{-3} \mathrm{~mol} \mathrm{dm}^{-3}$; (2) $1.5 \times 10^{-3} \mathrm{~mol} \mathrm{dm}^{-3}$; (3) $2.0 \times 10^{-3} \mathrm{~mol}$ $\mathrm{dm}^{-3}$; (4) $2.5 \times 10^{-3} \mathrm{~mol} \mathrm{dm}$; (5) $3.0 \times 10^{-3} \mathrm{~mol} \mathrm{dm}^{-3}$; (6) $3.5 \times 10^{-3}$ mol dm${ }^{-3}$; (7) $4.0 \times 10^{-3} \mathrm{~mol} \mathrm{dm}^{-3}$; (8) $4.5 \times 10^{-3} \mathrm{~mol} \mathrm{dm}^{-3}$; (9) $5.0 \times 10^{-3} \mathrm{~mol} \mathrm{dm}^{-3}$

of initial rate $\left(\mathrm{k}_{\mathrm{i}}\right)$ against the concentration of butanone exhibits initially a straight line passing through the origin and finally tends towards a limiting rate at higher concentrations of the substrate. However, variation in concentration of cyclo hexanone from $1.0 \times 10^{-3}$ to $2.0 \times 10^{-2}$ mol dm${ }^{-3}$ shows a first order dependence as the plot of initial rate $\left(\mathrm{k}_{\mathrm{i}}\right)$ versus [cyclohexanone] yields a straight line passing through the origin. Since the order with respect to each reactant in case of cyelohexanone is one, second order plots were also made.

Hydrogen ion concentration was varied from 0.25 to 2.5 mol dm${ }^{-3}$ at fixed concentrations of other reaction components constant at $\mathrm{I}=2.0 \mathrm{~mol} \mathrm{dm}{ }^{-3}$ in case of butanone. Rates do not depend on hydrogen ion concentration. However, rate increases with increasing hydrogen ion concentration at $\mathrm{I}=3.0 \mathrm{~mol} \mathrm{dm}^{-3}$ (adjusted by lithium perchlorate) and $30,35,40$ and $45^{\circ} \mathrm{C}$ respectively.

The concentration of ruthenium(III) chloride was varied from $1.0 \times 10^{-6}$ to $1.0 \times 10^{-5} \mathrm{~mol} \mathrm{dm}^{-3}$. The rate increases with increasing concentration of ruthenium(III) chloride and finally at higher concentrations tends towards a limiting value.

The effect of ionic strength was studied by employing lithium perchlorate from 0.2 to $1.0 \mathrm{~mol} \mathrm{dm}^{-3}$. Rate is independent of ionic strength in butanone reaction. However, the rate slightly decreases with increasing ionic strength in reaction of cyclohexanone which might be assigned to the 
Table 1. Effect of ionic strength in the reaction of ce(IV) and cyclohexanone $[\mathrm{ce}(\mathrm{IV})]=2.0 \times 10^{-3} \mathrm{~mol} \mathrm{dm}^{-3}$, [cyclhex $]=5.0 \times 10^{-3} \mathrm{~mol} \mathrm{dm}^{-3}$, $\left[\mathrm{H}_{2} \mathrm{SO}_{4}\right]=0.5 \mathrm{~mol} \mathrm{dm}^{-3,} 30^{\circ} \mathrm{C}$

\begin{tabular}{cc}
\hline$(\mathrm{I})$ & $10^{2}\left(\mathrm{k}_{\mathrm{i}}\right) \mathrm{dm}^{3} \mathrm{~mol}^{-1} \mathrm{~s}^{-1}$ \\
\hline 0.75 & 4.1 \\
1.0 & 4.0 \\
1.25 & 4.0 \\
1.50 & 3.8 \\
1.75 & 3.8 \\
2.0 & 3.7 \\
\hline
\end{tabular}

experimental uncertainty (Table 1).

The energy and entropy of activation were calculated to be (47 \pm 2.0$) \mathrm{KJ} \mathrm{mol}^{-1}$ and $(-98 \pm 6) \mathrm{JK}^{-1} \mathrm{~mol}^{-1}$ respectively in butanol and same were calculated to be $(63 \pm 3) \mathrm{KJ} \mathrm{mol}^{-1}$ and $(-67 \pm 5) \mathrm{JK}^{-1} \mathrm{~mol}^{-1}$ respectively in cyclohexanone, reactions in a conventional manner.

The kinetics of ruthenium(III) chloride catalyzed oxidation of butanone and uncatalyzed oxidation of cyclohexanone by cerium(IV) in $\mathrm{H}_{2} \mathrm{SO}_{4}$ medium respectively are complex owing to probably less precise speciation of sulphato-cerium(IV) species. Since hydrolytic forms of cerium(IV) are reported governed by equilibria (1) and (2).

$$
\begin{aligned}
& \mathrm{Ce}^{4+}+\mathrm{H}_{2} \mathrm{O} \stackrel{\mathrm{K}_{\mathrm{h}}^{\prime}}{\rightleftharpoons} \mathrm{Ce}(\mathrm{OH})^{3+}+\mathrm{H}^{+} \\
& \mathrm{Ce}(\mathrm{OH})^{3+}+\mathrm{H}_{2} \mathrm{O} \stackrel{\mathrm{K}_{\mathrm{h}}^{2}}{\rightleftharpoons} \mathrm{Ce}(\mathrm{OH})_{2}{ }^{2+}+\mathrm{H}^{+}
\end{aligned}
$$

The possibility of such hydrolytic species however, can be ruled out in $\mathrm{H}_{2} \mathrm{SO}_{4}$ medium. Cerium(IV) is known to form strong sulphato-cerium(IV) complexes in sulphuric acid medium. such sulphato-cerium(IV) species are governed by the following equilibria (3)-(5).

$$
\begin{aligned}
& \mathrm{Ce}^{4+}+\mathrm{HSO}_{4}{ }^{-} \stackrel{\mathrm{K}_{1}}{\rightleftharpoons} \mathrm{CeSO}_{4}{ }^{2+}+\mathrm{H}^{+} \\
& \mathrm{Ce}\left(\mathrm{SO}_{4}\right)^{2+}+\mathrm{HSO}_{4}{ }^{-} \stackrel{\mathrm{K}_{2}}{\rightleftharpoons} \mathrm{Ce}\left(\mathrm{SO}_{4}\right)_{2}+\mathrm{H}^{+} \\
& \mathrm{Ce}\left(\mathrm{SO}_{4}\right)_{2}+\mathrm{HSO}_{4}{ }^{-} \stackrel{\mathrm{K}_{3}}{\rightleftharpoons} \mathrm{HCe}\left(\mathrm{SO}_{4}\right)_{3}{ }^{-}
\end{aligned}
$$

The equilibrium constants $\mathrm{K}_{1}, \mathrm{~K}_{2}$ and $\mathrm{K}_{3}$ for steps (3) to (5) are reported to be 3500,200 and 20 at $25{ }^{\circ} \mathrm{C}$ respectively spectrophotometrically.

Since The species $\mathrm{Ce}\left(\mathrm{SO}_{4}\right)_{2}$ and $\mathrm{HCe}\left(\mathrm{SO}_{4}\right)_{3}{ }^{-}$are predominant forms of cerium(IV) in solutions containing $\left[\mathrm{H}_{2} \mathrm{SO}_{4}\right] \leq 2.0 \mathrm{~mol} \mathrm{dm}^{-3}$, the species $\mathrm{H}_{2} \mathrm{Ce}\left(\mathrm{SO}_{4}\right)_{4}{ }^{2-}$ governed by the equilibrium step (6) is only formed in $\left[\mathrm{H}_{2} \mathrm{SO}_{4}\right]>$ $2.0 \mathrm{~mol} \mathrm{dm}^{-3}$.

$$
\mathrm{HCe}\left(\mathrm{SO}_{4}\right)_{3}{ }^{-}+\mathrm{HSO}_{4}{ }^{-} \stackrel{\mathrm{K}_{4}}{\rightleftharpoons} \mathrm{H}_{2} \mathrm{Ce}\left(\mathrm{SO}_{4}\right)_{4}{ }^{2-}
$$

$\mathrm{K}_{4}$ was determined to be $0.6 \pm 0.1{ }^{\circ} \mathrm{C}$ at $20 \pm 2{ }^{\circ} \mathrm{C}$. Thus the species $\mathrm{H}_{2} \mathrm{Ce}\left(\mathrm{SO}_{4}\right)_{4}{ }^{2-}$ is ruled out to be the reactive form of cerium(IV) under experimental conditions.

\section{Mechanism of Ru(III) Chloride Catalyzed Oxida- tion of Butanone}

$\mathrm{Ru}(\mathrm{III})$ chloride catalysed oxidation of butanone exhibits first order with respect to $\mathrm{RuCl}_{3}$ (heretofore written as $\mathrm{Ru}^{\mathrm{III}}$ ) variable order with respect to butanone and zero order with respect to cerium(IV). Since rate does not depend upon the concentration of the oxidant, it is immaterial as to which cerium(IV) species participates in the reaction. Thus the variable order with respect to ketone can be accounted for the formation of an intermediate complex between the catalyst and the substrate. It is this oxidative rupturing of such a complex that is rate controlling step in the following envisaged mechanism consisting steps (7)-(10).

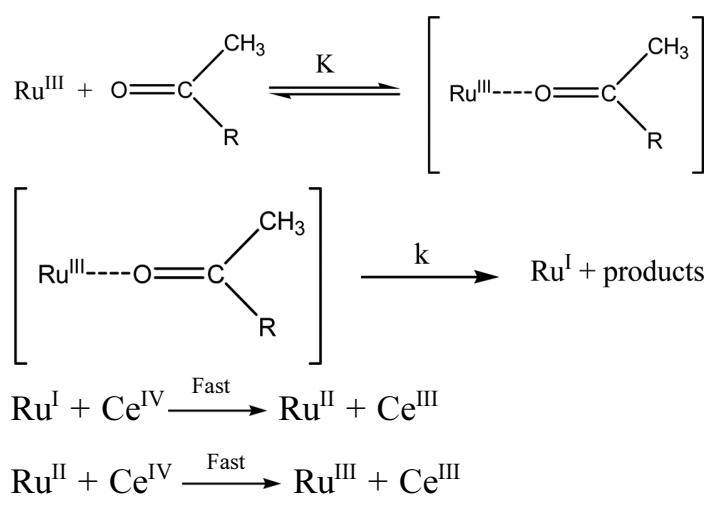

Therefore loss of cerium(IV) leads to the rate law (11) or (12)

$$
-\frac{1}{2} \frac{\mathrm{d}\left[\mathrm{Ce}^{\mathrm{IV}}\right]}{\mathrm{dt}}=\frac{\mathrm{kK}[\text { butanone }]\left[R u^{I I I}\right]}{1+\mathrm{K}[\text { butanone }]}
$$

Where $\left[\mathrm{Ru}^{\mathrm{III}}\right]$ and [butanone] are the gross analytical concentration of the catalyst and free equilibrium concentration of the substrate respectively. or

$$
\mathrm{k}^{\prime}=\frac{\mathrm{kK}[\text { butanone }]}{1+\mathrm{K}[\text { butanone }]}
$$

Where $\mathrm{k}^{\prime}$ is an observed pseudo first order rate constant.

A plot of $1 / \mathrm{k}^{\prime}$ versus [butanone $]^{-1}$ was made from eqn (12) yielded a straight line with non-zero intercept (Fig. 2) ' $\mathrm{k}$ ' was calculated from the intercept to be $(1.0 \pm 0.1),(1.4$ $\pm 0.2)$ and $(2.0 \pm 0.2) \mathrm{s}^{-1}$ at 30,35 and $40{ }^{\circ} \mathrm{C}$ respectively whereas $\mathrm{K}$ was calculated from the ratio of intercept and slope to be $(16 \pm 0.5),(15 \pm 0.5)$ and $(14 \pm 0.4) \mathrm{mol} \mathrm{dm}^{-3}$ at 30,35 and $40{ }^{\circ} \mathrm{C}$ respectively and $\mathrm{I}=1.0 \mathrm{~mol} \mathrm{dm}^{-3}$. These 


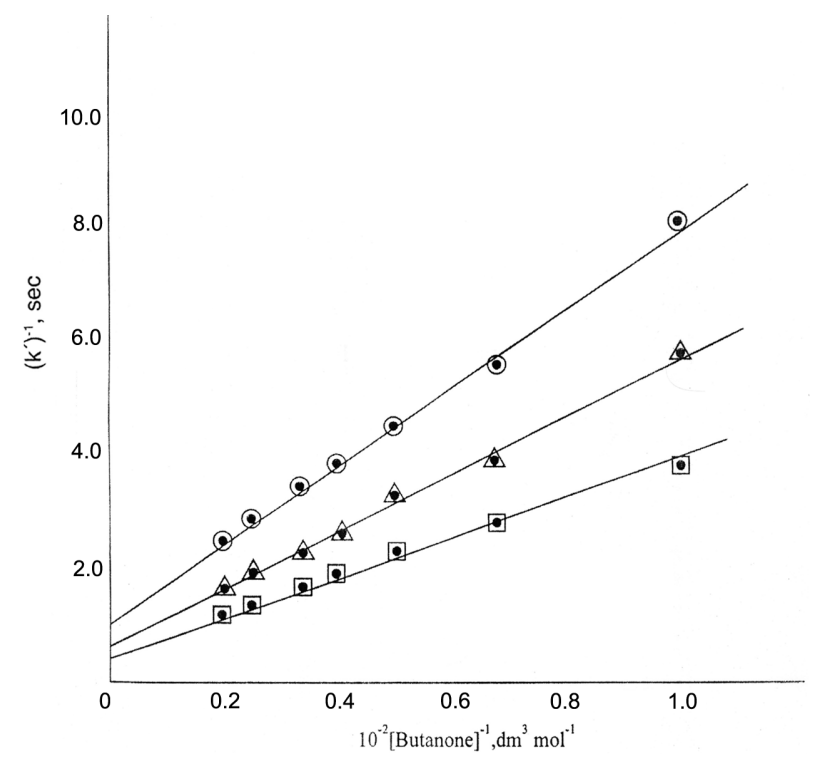

Fig. 2. PLOTS OF $\left(\mathrm{k}^{\prime}\right)^{-1}$ vs $[\text { Butanone }]^{-1}[\mathrm{Ce}(\mathrm{IV})]=2.0 \times 10^{-3} \mathrm{~mol}$ $\mathrm{dm}^{-3} ;[\mathrm{Ru}(\mathrm{III})] .5 .0 \times 10^{-6} \mathrm{~mol} \mathrm{dm}^{-3} ;\left[\mathrm{H}_{2} \mathrm{SO}_{4}\right]=5.0 \times 10^{-6} \mathrm{~mol} \mathrm{dm}^{-3} ; \odot$,

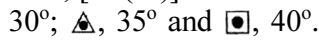

formation constants appear to be constant ascribing complex to be thermally stable.

Further any evidence neither kinetic nor otherwise was obtained for the formation of free radical. However, free radical can not be ruled out only on this premise. There is every possibility of formation of free radical. As soon as it is formed, it immediately reacts with the oxidant in the solvent cage before escaping out.

\section{Oxidation of Cyclohexanone by Cerium(IV)}

The kinetic contrary to ruthenium(III) catalysed oxidation of butanone results in the oxidation of cyclohexanone by cerium(IV) are quite interesting. The reaction is second order-first order with respect to each reactant and the rate increases with increasing concentration of hydrogen ion. As already discussed, it is not the bare ceric ion but various sulphato-cerium(IV) species that govern the reaction events in cerium(IV) oxidations of cyclohexane in sulphuric acid medium.

Hydrogen ion dependence in the reactions of cerium(IV) is generally complex. It is not only due to interplay of hydrogen ion dependent species of cerium(IV) but also sometimes due to the hydrogen ion dependent substrate species. $\mathrm{Ce}\left(\mathrm{SO}_{4}\right)_{2}$ is reported to be an active sulpahtocerium(IV) species. If $\mathrm{Ce}\left(\mathrm{SO}_{4}\right)_{2}$ is the reactive form, ${ }^{14}$ hydrogen ion dependence can not be co-related to this species. Thus there is every possibility that both keto and protonated keto forms are reactive towards sulphato-
cerium(IV) species to account for the hydrogen ion dependence of the rate.

Since the co-ordination sites of cerium(IV) are significantly saturated by sulphate ions, the chances of incorporation of the substrate in the co-ordination shell of the metal-ion are significantly minimized. Nevertheless, the weak complexation between $\mathrm{Ce}\left(\mathrm{SO}_{4}\right)_{2}$ and cyclohexanone can not be ruled out on the premise of a lower energy pathway. In view of such arguments, following reaction mechanism can be proposed.

$$
\begin{aligned}
& \text { Ketone }+\mathrm{H}^{+} \stackrel{\mathrm{K}^{\prime}}{\longrightarrow}>\mathrm{COH}^{+} \\
& \mathrm{Ce}\left(\mathrm{SO}_{4}\right)_{2}+>\mathrm{CO} \stackrel{\mathrm{K}_{1}^{\prime}}{\longrightarrow}\left[\mathrm{Ce}\left(\mathrm{SO}_{4}\right)_{2} \ldots . . . \mathrm{OC}<\right] \\
& {\left[\mathrm{Ce}\left(\mathrm{SO}_{4}\right)_{2} \ldots . . \mathrm{OC} \stackrel{\mathrm{k}_{1}^{\prime}}{\longrightarrow}\right. \text { Products }} \\
& \mathrm{Ce}\left(\mathrm{SO}_{4}\right)_{2}+\mathrm{H}^{+} \mathrm{OC}<\stackrel{\mathrm{k}_{2}^{\prime}}{\longrightarrow}\left[\mathrm{Ce}\left(\mathrm{SO}_{4}\right) \cdots \cdots \cdot \mathrm{H}^{+} \mathrm{OC}<\right] \\
& {\left[\mathrm{Ce}\left(\mathrm{SO}_{4}\right)_{2} \ldots . . .{ }^{+} \mathrm{HOC}<\stackrel{\mathrm{k}_{2}^{\prime}}{\longrightarrow}\right. \text { Products }}
\end{aligned}
$$

Such a mechanism leads to the rate law (18)

$$
-\frac{1}{2} \frac{\mathrm{d}\left[\mathrm{Ce}^{\mathrm{IV}}\right]}{\mathrm{dt}}\left(\mathrm{k}_{1} \mathrm{~K}_{1}^{\prime}+\mathrm{k}_{2}^{\prime} \mathrm{K}_{2}^{\prime} \mathrm{K}^{\prime}\left[\mathrm{H}^{+}\right]\right)\left[\mathrm{Ce}\left(\mathrm{SO}_{4}\right)_{2}\right][\text { Ketone }]
$$

Since equilibrium constants $\mathrm{K}_{1}{ }^{\prime}$ and $\mathrm{K}_{2}{ }^{\prime}$ are significantly small, eqn (18) is further reduced to eqn (19)

$$
-\frac{1}{2} \frac{\mathrm{d}\left[\mathrm{Ce}^{\mathrm{IV}}\right]}{\mathrm{dt}}\left(\mathrm{k}_{1}+\mathrm{k}_{2} \mathrm{~K}^{\prime}\left[\mathrm{H}^{+}\right]\right)\left[\mathrm{Ce}\left(\mathrm{SO}_{4}\right)_{2}\right][\text { Ketone }]
$$

Further, the concentration of $\mathrm{Ce}\left(\mathrm{SO}_{4}\right)_{2}$ species in terms of total cerium(IV) concentration is given by eqn (20)

$$
\left[\mathrm{Ce}\left(\mathrm{SO}_{4}\right)_{2}\right]=\left[\mathrm{Ce}(\mathrm{IV}) /\left(1+\mathrm{K}_{3}\left[\mathrm{HSO}_{4}^{-}\right]\right)\right]
$$

Substituting $\left[\mathrm{Ce}\left(\mathrm{SO}_{4}\right)_{2}\right]$ from eqn (20) into eqn (19), eqn (21) or eqn (22) is obtained:

$$
-\frac{1}{2} \frac{\mathrm{d}\left[\mathrm{Ce}^{\mathrm{IV}}\right]}{\mathrm{dt}}\left(\mathrm{k}_{1}+\mathrm{k}_{2} \mathrm{~K}^{\prime}\left[\mathrm{H}^{+}\right]\right) \frac{\left[\mathrm{Ce}^{\mathrm{IV}}\right][\text { Ketone }]}{\left(1+\mathrm{K}_{3}\left[\mathrm{HSO}_{4}^{-}\right]\right)}
$$

or

$$
\mathrm{k}=\left(\mathrm{k}_{1}+\mathrm{k}_{2} \mathrm{~K}^{\prime}\left[\mathrm{H}^{+}\right]\right) /\left(1+\mathrm{K}_{3}\left[\mathrm{HSO}_{4}^{-}\right]\right)
$$

Where ' $\mathrm{k}$ ' is second order rate constant as collected in (Table 2).

A plot of $\mathrm{k}$ versus $\left[\mathrm{H}^{+}\right]$was made from eqn (22) at constant bisulphate concentration that yielded a straight line with non-zero intercept, (Fig. 3), 'k' from the intercept was calculated to be $(1.3 \pm 0.2),(2.2 \pm 0.2),(4.7 \pm 0.2)$ and $(6.7 \pm 0.3) \mathrm{dm}^{3} \mathrm{~mol}^{-1} \mathrm{~s}^{-1}$ at $30,35,40$ and $45^{\circ} \mathrm{C}$ respectively at $\mathrm{I}=3.0 \mathrm{~mol} \mathrm{dm}^{-3}$. Similarly $\mathrm{k}_{2} \mathrm{~K}^{\prime}$ were calculated to be $(1 \pm 0.1),(1.5 \pm 0.1),(1.9 \pm 0.1)$ and $(2.3 \pm 0.1) \mathrm{S}^{-1}$ at 
Table 2. Initial rates $\left(\mathrm{k}_{\mathrm{i}}\right)$ and second order rate constants $(\mathrm{k})$ in the reaction of cyclohexanone and cerium(IV) in sulphuric acid medium $\left[\mathrm{H}_{2} \mathrm{SO}_{4}\right]=0.5 \mathrm{~mol} \mathrm{dm}^{-3}, 30^{\circ} \mathrm{C}$

\begin{tabular}{|c|c|c|c|}
\hline $\begin{array}{l}10^{3}\left[\mathrm{Ce}^{\mathrm{IV}}\right] \\
\mathrm{mol} \mathrm{dm}\end{array}$ & $\begin{array}{c}10^{3}[\text { cychex }] \\
\text { mol dm}^{-3}\end{array}$ & 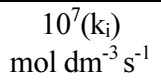 & $\begin{array}{c}10^{2}(\mathrm{k}) \\
\mathrm{dm}^{3} \mathrm{~mol}^{-1} \mathrm{~s}^{-1}\end{array}$ \\
\hline 1.0 & 5.0 & 2.17 & $4.0(4.3)$ \\
\hline 1.5 & 5.0 & 3.17 & $4.0(4.2)$ \\
\hline 2.0 & 5.0 & 4.17 & $4.1(4.2)$ \\
\hline 2.5 & 5.0 & 5.42 & $4.1(4.3)$ \\
\hline 3.0 & 5.0 & 6.25 & $4.1(4.2)$ \\
\hline 3.5 & 5.0 & 7.50 & $4.1(4.3)$ \\
\hline 4.0 & 5.0 & 8.33 & $4.1(4.2)$ \\
\hline 4.5 & 5.0 & 9.17 & $4.1(4.1)$ \\
\hline 1.0 & 10.0 & 4.0 & $4.1(4.0)$ \\
\hline 1.5 & 10.0 & 6.33 & $4.0(4.2)$ \\
\hline 2.0 & 10.0 & 8.33 & $4.1(4.2)$ \\
\hline 2.5 & 10.0 & 10.0 & $4.1(4.0)$ \\
\hline 3.0 & 10.0 & 11.7 & $4.0(3.9)$ \\
\hline 3.5 & 10.0 & 15.0 & $4.0(4.3)$ \\
\hline 4.0 & 10.0 & 16.7 & $4.0(4.2)$ \\
\hline 4.5 & 10.0 & 18.3 & $4.0(4.1)$ \\
\hline 5.0 & 10.0 & 20.0 & $4.1(4.0)$ \\
\hline 1.0 & 20.0 & 7.78 & $4.0(3.9)$ \\
\hline 1.5 & 20.0 & 12.22 & $4.0(4.1)$ \\
\hline 2.0 & 20.0 & 16.67 & $4.0(4.2)$ \\
\hline 2.5 & 20.0 & 20.8 & $4.1(4.2)$ \\
\hline 3.0 & 20.0 & 23.6 & 4.1(3.9) \\
\hline 3.5 & 20.0 & 29.2 & $4.0(4.2)$ \\
\hline 4.0 & 20.0 & 33.3 & $4.0(4.0)$ \\
\hline 4.5 & 20.0 & 34.7 & $4.0(3.9)$ \\
\hline 5.0 & 20.0 & 41.7 & $4.1(4.2)$ \\
\hline 2.0 & 1.0 & 0.83 & $4.1(4.0)$ \\
\hline 2.0 & 3.0 & 2.40 & $4.1(4.0)$ \\
\hline 2.0 & 4.0 & 3.30 & $4.0(4.1)$ \\
\hline 2.0 & 5.0 & 4.17 & $4.1(4.1)$ \\
\hline 2.0 & 6.0 & 5.0 & $4.0(4.2)$ \\
\hline 2.0 & 8.0 & 6.25 & 4.1(3.9) \\
\hline 2.0 & 10.0 & 8.33 & $4.1(4.2)$ \\
\hline 2.0 & 15.0 & 12.5 & $4.1(4.2)$ \\
\hline 2.0 & 20.0 & 16.67 & $4.0(4.2)$ \\
\hline 3.0 & 1.0 & 1.25 & $4.1(4.2)$ \\
\hline 3.0 & 2.0 & 2.5 & $4.1(4.2)$ \\
\hline 3.0 & 4.0 & 4.79 & $4.1(4.0)$ \\
\hline 3.0 & 5.0 & 6.25 & $4.1(4.2)$ \\
\hline 3.0 & 6.0 & 7.08 & 4.1(3.9) \\
\hline 3.0 & 8.0 & 10.42 & $4.1(4.3)$ \\
\hline 3.0 & 10.0 & 11.67 & $4.1(3.9)$ \\
\hline 3.0 & 15.0 & 17.7 & 4.1(3.9) \\
\hline 3.0 & 20.0 & 23.6 & 4.1(3.9) \\
\hline
\end{tabular}

Values in parenthesis were obtained from initial rates.

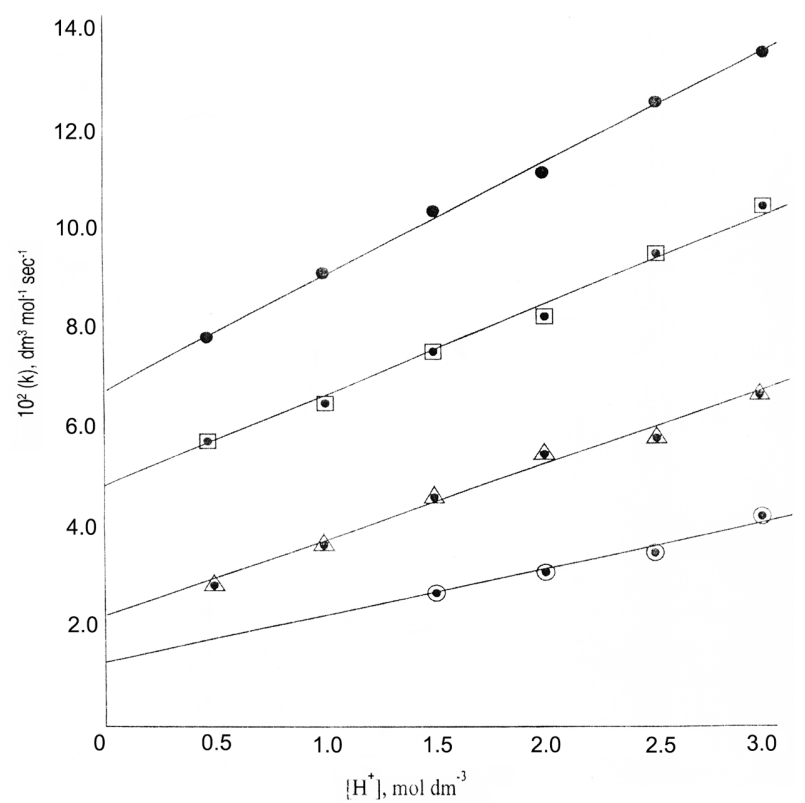

Fig. 3. PLOTS OF $\left(\mathrm{H}^{+}\right)[\mathrm{Ce}(\mathrm{IV})]=2.0 \times 10^{-3} \mathrm{~mol} \mathrm{dm}^{-3}$; [Cychex] $=1.0 \times 10^{-2} \mathrm{~mol} \mathrm{dm}^{-3} ;\left[\mathrm{H}_{2} \mathrm{SO}_{4}\right]=0.5 \mathrm{~mol} \mathrm{dm}^{-3} ;[\mathrm{I}]=3.0 \mathrm{~mol} \mathrm{dm}^{-3} ; \odot$, $30^{\circ} ; \stackrel{\Delta}{\circ}, 35^{\circ} ; \square, 40^{\circ}$ and $\mathbf{0}, 45^{\circ} \mathrm{C}$.

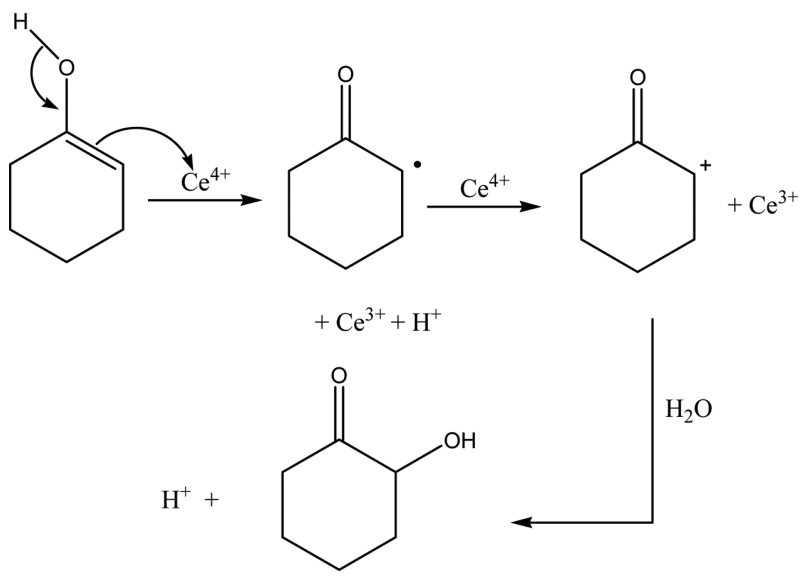

Scheme 1.

$30,35,40$ and $45^{\circ} \mathrm{C}$ respectively at $\mathrm{I}=3.0 \mathrm{~mol} \mathrm{dm}^{-3}$. If $\mathrm{K}^{\prime}$ is taken in to account, the value of $\mathrm{k}_{2}$ is much larger than uncatalyzed rate constants ' $\mathrm{k}_{1}$ '.

The mode of electron transfer in cyclohexanone in acid catalyzed path can be visualized from the following Scheme 1.

\section{CONCLUSIONS}

Ruthenium(III) chloride catalyzed kinetics of oxidation of butanone by cerium(IV) in $\mathrm{H}_{2} \mathrm{SO}_{4}$ medium exhibit zero order dependence with respect to the oxidant. Therefore, discussion regarding sulphato-cerium(IV) species regard- 
ing their speciation is not required. The complex dependence on ketone is analyzed through an intermediate complex between catalyst and the substrate.

In case of cyclohexanone the species $\mathrm{Ce}\left(\mathrm{SO}_{4}\right)$ is formed to be the reactive species of cerium(IV). Since order with respect to cerium(IV) is one and overall order is two, the reaction occurs without enolization of the ketone. It is the protonated form of cyclohexanone that accounts for hydrogen ion dependence. A reaction scheme has been tentatively suggested for this reaction.

\section{REFERENCES}

1. Devra, V.; Sharma, Indu; Sharma, P. D. Int. J. Chem. Kinet. 1993, 245, 538.

2. Ho, T. L. Synthesis 1973, 347.

3. Galliani, G.; Rindone, B.; Scolastico, C. Synth. Commun. 1975, 5, 319.

4. McAuley, A. Coord. Chem. Rev. 1970, 5, 245.
5. Sherril, M. S.; King, C. B.; Spoonen, R. C. J. Am. Chem. Soc. 1943, 65, 170.

6. Berka, A.; Vulterin, J.; Zyka, J. Newer Redox Titrants; Pergamon Press: UK, 1965.

7. Farokhi, S. A.; Kini, A. K.; Nandibewor, S. T. Oxid. Commun. 2007, 20(1), 141.

8. Singh, K.; Tripathi, H.; Awasthi, A.; Shrivastva, S. N. Oxid. Commun. 2001, 24(3), 388.

9. Singh, B.; Sisodia, A. K.; Chand, R. Oxid. Commun. 1986, 9, 219.

10. Singh, M. P.; Singh, H. S.; Verma, M. K. J. Phys. Chem. 1980, 84, 256.

11. Pillai, G. C.; Rajaman, J.; Kuriacose, J. C. Ind. J. Chem. A, 1977, 15(A), 608.

12. Panigrahi, G. D.; Mipro, P. K. Ind. J. Chem. 1976, 14(A), 579.

13. Latshaw, M. J. Am. Chem. Soc. 1925, 47, 793.

14. Agarwal Anju, Sharma Gayatri, Khandelwal, C. L.; Sharma, P. D. Inorg. React. Mech. 2002, 4, 233 and references therein. 